\title{
Additively manufactured titanium scaffolds and osteointegration - meta-analyses and moderator-analyses of in vivo biomechanical testing
}

Simon Cleemput ${ }^{1,2^{*}}$ (D) Stijn E. F. Huys ${ }^{3+}$, Robbert Cleymaet ${ }^{2}$, Wilfried Cools ${ }^{4}$ and Maurice Y. Mommaerts ${ }^{2}$

\begin{abstract}
Introduction: Maximizing osteointegration potential of three-dimensionally-printed porous titanium (3DPPT) is an ongoing focus in biomaterial research. Many strategies are proposed and tested but there is no weighted comparison of results.

Methods: We systematically searched Pubmed and Embase to obtain two pools of 3DPPT studies that performed mechanical implant-removal testing in animal models and whose characteristics were sufficiently similar to compare the outcomes in meta-analyses (MAs). We expanded these MAs to multivariable meta-regressions (moderator analysis) to verify whether statistical models including reported scaffold features (e.g., "pore-size", "porosity", "type of unit cell") or post-printing treatments (e.g., surface treatments, adding agents) could explain the observed differences in treatment effects (expressed as shear strength of bone-titanium interface).

Results: "Animal type" (species of animal in which the 3DPPT was implanted) and "type of post-treatment" (treatment performed after 3D printing) were moderators providing statistically significant models for differences in mechanical removal strength. An interaction model with covariables "pore-size" and "porosity" in a rabbit subgroup analysis (the most reported animal model) was also significant. Impact of other moderators (including "time" and "location of implant") was not statistically significant.

Discussion/conclusion: Our findings suggest a stronger effect from porosity in a rat than in a sheep model. Additionally, adding a calcium-containing layer does not improve removal strength but the other post-treatments do. Our results provide overview and new insights, but little narrowing of existing value ranges. Consequent reporting of 3DPPT characteristics, standardized comparison, and expression of porosity in terms of surface roughness could help tackle these existing dilemmas.
\end{abstract}

Keywords: 3D printing, Titanium, Animal experimentation, Meta-analysis

\footnotetext{
* Correspondence: simoncleemput@gmail.com

${ }^{\dagger}$ Simon Cleemput and Stijn E. F. Huys are co-first author.

'Doctoral School of Life Sciences and Medicine, Vrije Universiteit Brussel, 1090 Brussels, Belgium

${ }^{2}$ European Face Centre, Universitair Ziekenhuis Brussel, Vrije Universiteit Brussel, 1090 Brussels, Belgium

Full list of author information is available at the end of the article
}

C C The Author(s). 2021 Open Access This article is licensed under a Creative Commons Attribution 4.0 International License, which permits use, sharing, adaptation, distribution and reproduction in any medium or format, as long as you give appropriate credit to the original author(s) and the source, provide a link to the Creative Commons licence, and indicate if changes were made. The images or other third party material in this article are included in the article's Creative Commons licence, unless indicated otherwise in a credit line to the material. If material is not included in the article's Creative Commons licence and your intended use is not permitted by statutory regulation or exceeds the permitted use, you will need to obtain permission directly from the copyright holder. To view a copy of this licence, visit http://creativecommons.org/licenses/by/4.0/ The Creative Commons Public Domain Dedication waiver (http://creativecommons.org/publicdomain/zero/1.0/) applies to the data made available in this article, unless otherwise stated in a credit line to the data. 


\section{Background}

Regarding biocompatibility and appropriate biomechanical behavior, titanium (Ti) and its alloys surpass most other metals used for medical implantation purposes. The stabile passivation of $\mathrm{Ti}$ into $\mathrm{TiO}_{2}$ makes implants comprising $\mathrm{Ti}$ and $\mathrm{Ti}$ alloys well shielded from the surrounding tissue, preventing them from further corrosion and protecting the surrounding tissue from possible toxicity [1]. Additionally the high fatigue and tensile strength at a low density and low elastic modulus make constructs comprising Ti6Al4V, TiALNb, and the higher grade commercially pure $\mathrm{Ti}$ ( $\mathrm{CP}$ gr 3 and 4) less prone to causing stress-shielding and suitable for osteointegration (OI) subject to dynamic loading [2]. The commercial viability of 3D metal printing has emerged in the last decade. Because this production method is often applied to fabricate light, thin, intricate structures, the search for an appropriate printing metal has also granted $\mathrm{Ti}$ a favorable position. For implantation purposes, 3D printing using titanium means that implants can now be fabricated in a highly personalized manner because of a digital workflow that starts from high-resolution images that are often readily available (e.g., medical CT scans). Another advantage (a consequence of the "additive" instead of more conventional "subtractive" approach) of $3 \mathrm{D}$ printing is that constructs can now be fabricated that are fully and internally porous, with open, interconnected pores and reaching the full internal depth of the construct.

Although the primary intent to print titanium implants porously was to further lower the stiffness and thus the possible stress-shielding effect (Ti6Al4V has a Young's modulus of $104 \mathrm{GPa}$, still approximatively 5 times higher than that of cortical bone $(20 \mathrm{GPa})$ and 10 times higher than that of trabecular bone $(10 \mathrm{GPa})$ [3]), the porous surface is also believed to aid in OI. Much like the porous metal outer layers made with conventional, subtractive production methods (such as powder metallurgy using space-holding agents), the 3D-printed pores provide space for the surrounding bone tissue to grow into and add contact surface (or surface roughness) to the construct. This principle is established and has been applied in medical devices such as cementless hip prostheses, spinal fusion cages, and dental implants for almost 2 decades. Achieving total interconnectivity of the individual pores and control of the exact number (= "porosity"), dimensions (= "pore-size"), and shape (= "unit cell") of the pores is a new given.

3DPPT has the potential to evolve into one of the most successful OI strategies, and the research field is thriving. The literature reporting on well toughedthrough lattice designs and enhancing post-printing treatments is rapidly increasing, aiming to achieve a maximal OI. However, the designs and treatments are becoming increasingly specific and are often tested in vitro or in very specific in vivo models, making it difficult to draw conclusions that apply to 3DPPT in general, or to slightly different designs or models. Thus, regarding the importance of 3DPPT features, namely lattice design parameters (e.g., "pore-size", "porosity", and "type of unit-cell") and effectiveness of applied post-printing treatments (e.g., coatings and surface treatments), the current literature offers broad ranges of values and few consensuses (examples listed in the Discussion section). However, none of these data are sharply defined and none are the result of any systematic gathering and weighted comparison of outcomes.

Considering that the literature is becoming extensive and that several uncertainties remain, we subjected 3DPPT to statistical analysis. Unmistakably realizing the difficulty in making valid comparisons in this research field, we conducted a systematic literature review (SR) with a meta-analysis (MA) and meta-regression (moderator-analysis) to respond to our research questions "How do the results of studies evaluating the OI of different 3DPPT designs and treatments compare to each other, and to which extent are differences in the results statistically linked to design parameters or post-printing treatments?"

Considering all possible approaches and to provide an overview of tangible OI results, we evaluated only in vivo animal studies, focusing on OI evaluation using mechanical removal testing.

\section{Main text \\ Methods}

Our systematic review and meta-analyses were performed according to the CAMARADES ("Collaborative Approach to Meta-Analysis and Review of Animal Data from Experimental Studies) guidelines (http://www.dcn. ed.ac.uk/camarades/default.htm) [4]. Our protocol was registered at PROSPERO (https://www.crd.york.ac.uk/ prospero/display_record.php?RecordID=211733), and we reported the information according to the PRISMA 2009 checklist.

\section{Search strategy}

We searched the electronic databases of Pubmed (Medline) and Embase with the search terms listed in Table 1 connected by the Boolean search words. Being careful not to overlook any animal models, we did not include an exhaustive list of animals, but rather manually selected the in vivo studies from our search results.

\section{Study selection}

We exported the literature search into Endnote X9 and removed duplicates. After that, study selection was 
Table 1 Literature search

\begin{tabular}{|c|c|c|}
\hline Pubmed & Embase & \\
\hline $\begin{array}{l}\text { "Metals"[Mesh] OR metal[tiab] OR } \\
\text { "Titanium"[Mesh] OR Ti[tiab] OR } \\
\text { titanium[tiab] OR ti6al4v[tiab] OR } \\
\text { ti6alv4[tiab] OR Ti-6Al-4V[tiab] OR } \\
\text { "Tantalum"[Mesh] } \\
\text { OR tantalum[tiab] OR Ta[tiab] }\end{array}$ & $\begin{array}{l}\text { 'metal'/exp OR 'metal':ti,ab,kw OR } \\
\text { 'titanium'/exp OR 'titanium':ti,ab,kw OR } \\
\text { ti:ti,ab,kw OR 'titanium alloy':ti,ab,kw } \\
\text { OR 'tantalum'/exp OR 'ta':ti,ab,kw OR } \\
\text { 'tantalium':ti,ab,kw }\end{array}$ & $\begin{array}{l}\text { (The focus was } \\
\text { titanium, but we also } \\
\text { included tantalum in } \\
\text { the search (as it is a } \\
\text { similar, refractory } \\
\text { metal), and } \\
\text { broadened the search } \\
\text { to "metals" (in order } \\
\text { not to overlook } \\
\text { anything.) }\end{array}$ \\
\hline AND & AND & \\
\hline $\begin{array}{l}\text { "Porosity"[Mesh] OR porous*[tiab] } \\
\text { OR mesoporous[tiab] OR } \\
\text { microporous[tiab] OR } \\
\text { macroporous[tiab] OR poros*[tiab] } \\
\text { OR "Tissue Scaffolds"[Mesh] OR } \\
\text { scaffold*[tiab] OR lattice[tiab] }\end{array}$ & $\begin{array}{l}\text { ('porosity'/exp OR 'pore size'/exp OR } \\
\text { poros*:ti,ab,kw OR porous*:ti,ab,kw OR } \\
\text { 'microporous':ti,ab,kw OR } \\
\text { 'mesoporous':ti,ab,kw OR } \\
\text { 'macroporous':ti,ab,kw OR 'tissue } \\
\text { scaffold'/exp OR scaffold*:ti,ab,kw OR } \\
\text { tissue) AND scaffold*:ti,ab,kw }\end{array}$ & $\begin{array}{l}\text { (The implants had to } \\
\text { be some kind of } \\
\text { "porous" ; other terms } \\
\text { included "scaffold" } \\
\text { and lattice".) }\end{array}$ \\
\hline AND & AND & \\
\hline $\begin{array}{l}\text { "Printing, Three-Dimensional"[Mesh] } \\
\text { OR 3D-print*[tiab] OR 3-d- } \\
\text { print*[tiab] OR 3-dimensional- } \\
\text { print*[tiab] OR three-dimensional- } \\
\text { print*[tiab] OR additive- } \\
\text { manufact*[tiab] OR AM[tiab] OR } \\
\text { stereolithography[tiab] OR selective- } \\
\text { laser-melt*[tiab] OR SLM[tiab] OR } \\
\text { electron-beam-melt*[tiab] OR } \\
\text { EBM[tiab] OR "Computer-Aided } \\
\text { Design"[Mesh] OR Computer Aided } \\
\text { Design*[tiab] OR Computer-Assisted } \\
\text { Design*[tiab] OR Computer Assisted } \\
\text { Design*[tiab] OR Computer-Assisted } \\
\text { Manufacturing*[tiab] OR Computer } \\
\text { Assisted Manufacturing*[tiab] OR } \\
\text { CAD-CAM[tiab] OR "Tissue } \\
\text { Engineering"[Mesh])) }\end{array}$ & $\begin{array}{l}\text { 'three dimensional printing'/exp OR '3-d } \\
\text { printing':ti,ab,kw OR '3d } \\
\text { printing':ti,ab,kw OR 'additive } \\
\text { manufacturing'/exp OR 'selective laser } \\
\text { melting'/exp OR 'electron beam } \\
\text { melting'/exp OR 'computer aided } \\
\text { design'/exp OR 'computer assisted } \\
\text { design':ti,ab,kw OR 'computer-aided } \\
\text { design':ti,ab,kw OR 'computer aided } \\
\text { manufacturing':ti,ab,kw OR 'tissue } \\
\text { engineering'/exp }\end{array}$ & $\begin{array}{l}\text { (The implants had to } \\
\text { be 3D printed. We } \\
\text { thus included } \\
\text { synonyms of } 3 D \\
\text { printing, the most } \\
\text { popular methods of } \\
\text { 3D printing and 3D } \\
\text { design methods.) }\end{array}$ \\
\hline 1734 results & 1607 results & $\begin{array}{l}\text { Search last } \\
\text { performed on } \\
05-09-2020\end{array}$ \\
\hline
\end{tabular}

performed using Rayyan online software, applying a 3step approach. We included original animal studies (analytical, experimental research) that evaluated OI of 3DPPT (or Tantalum) implants mechanically in a measurable, quantitative way. We exclude studies that only performed histomorphological or radiological evaluation.
Next, we selected the studies that performed implant removal testing (push-out, pull-out, or torque-out). We excluded studies using three-point bending and range of motion (ROM) testing because they do not allow for clear identification of the forces applied to the boneimplant interface. The remaining studies were divided 
into two pools to perform two separate MAs. The studies were allocated based on the type of intervention performed but must be comparable to a very similar control group. MA1 comprises studies that compared the OI of an experimental group (Exp) of 3DPPT against a control group (Co) of solid, non-porous, 3D printed titanium. ${ }^{1}$ MA2 comprises studies that compared the OI of an experimental group (Exp) of post-treated 3DPPT against a control group (Co) of non-post treated 3DPPT. ${ }^{2}$

\section{Data extraction}

We read the full-text articles of the obtained publications and gathered the following information: study characteristics (author, title, and year of publication); implant shape and dimensions; characteristics of the 3Dprinted porous structure (pore-size, porosity, and unit cell); 3D printing method; type of titanium (alloy) used; post-printing treatment; animal model used; site of implantation, type of bone-tissue present at the site; method of implantation; and fit of the implant in the bone.

We also gathered the reported outcomes of the OI evaluation, which, depending on the type of mechanical testing performed, were the peak removal force or load (N) (when the implant was pushed or pulled out of a resected bone specimen), peak removal torque (Nmm) or torsion force $(\mathrm{N} / \mathrm{cm})$ (in the case of torque-out testing) and shear strength or modulus (Mpa) (the peak removal force or load divided by the bone-titanium interface area subject to the removal force).

The selection and data extraction processes were performed by two researchers (RC and SC) who worked independently and resolved discrepancies by consensus. Whenever desired information was not reported, the authors of the publication were contacted and requested to submit information by e-mail. Twenty-four authors were e-mailed from March 21 to May 18, 2020. Whenever a request for an outcome value was not met, online measuring software (https://apps.automeris.io/wpd/) was used to derive an estimated value from published graphs. This measuring process was also independently performed by these two researchers ( $\mathrm{RC}$ and $\mathrm{SC}$ ), and the final values used for statistical analyses were the calculated means of their estimations.

\section{Data synthesis and statistical method}

We performed two separate MAs of aggregate data of the included mechanical testing using implant removal

\footnotetext{
${ }^{1}$ Exp and Co had the same composition as Ti, with identical implant shape and dimensions, implanted in the same way, at the same location, in the same animal model.

${ }^{2}$ Same as ${ }^{1}$, but Exp and Co also shared the same design parameters ("pore-size", "porosity", "unit cell", and "Struth-size") for their porous structure.
}

studies. We chose to convert all the obtained outcomes and standard deviations (SDs) that were not already expressed as such to the common unit "shear strength" (Mpa) because this unit balances discrepancies caused by differences in size-that is, the contact surface of the implants. For this task, we applied Eq. 1), with force (F) representing the obtained outcome or SD and area (A) representing the shear surface of the implant and bone during implant removal testing. The shear surface (A) itself was calculated from the obtained "implant dimensions" (height and diameter) according to Eq. 2), most often as the mantle surface of the implant (perpendicular to the direction of the removal force applied) and always in strict accordance with the study specifications (considering the depth of implantation or possible nongeometric shape). In the case of torque-out testing, (F) was calculated according to Eq. 3), as the torque value (tau) divided by the radius of the implant (cylinder or screw).

Formulae and equations

$$
\begin{aligned}
& \text { shear strenght }=\text { force/surface } S S=F / A \\
& A_{\text {cylinder,screw,prism or block }}=\text { base } \times \text { height } A=b \times h \\
& \text { Torque outforce } \text { cylinder }, \text { screw }=\text { torque/distance } \\
& F=\text { tau } \text { radius }_{\text {cylinder,screw }}
\end{aligned}
$$

From the obtained or converted outcomes and SDs, standardized mean differences (SMDs) and 95\% confidence intervals (CIs) were calculated using Hedges' g method. We used $\tau^{2}$ (calculated using the HartungKnapp-Sidik-Jonkman (HKSJ) method) and $\mathrm{I}^{2}$ to quantify heterogeneity. The obtained MAs were tested for outliers and finally expanded to multivariable meta-regressions (moderator analyses) to examine the effects of the variables "time", "animal model", "location of implantation", "pore-size", "porosity", "Struth size" and "type of unit cell" (for MA 1) and "time", "animal model", "location of implantation", and "type of surface treatment" (for MA 2) on the calculated treatment effect (TE).

\section{Quality and risk of bias assessment}

We used Syrcle's Risk of Bias tool (ROB) to evaluate the methodological quality of the studies included in the 2 MAs. This tool is derived from Cochrane's ROB tool and is preferred by CAMARADES [4].

\section{Results}

Study selection

As shown in Fig. 1, step 1 in our selection process obtained 97 studies, of which 43 remained after step 2 . 


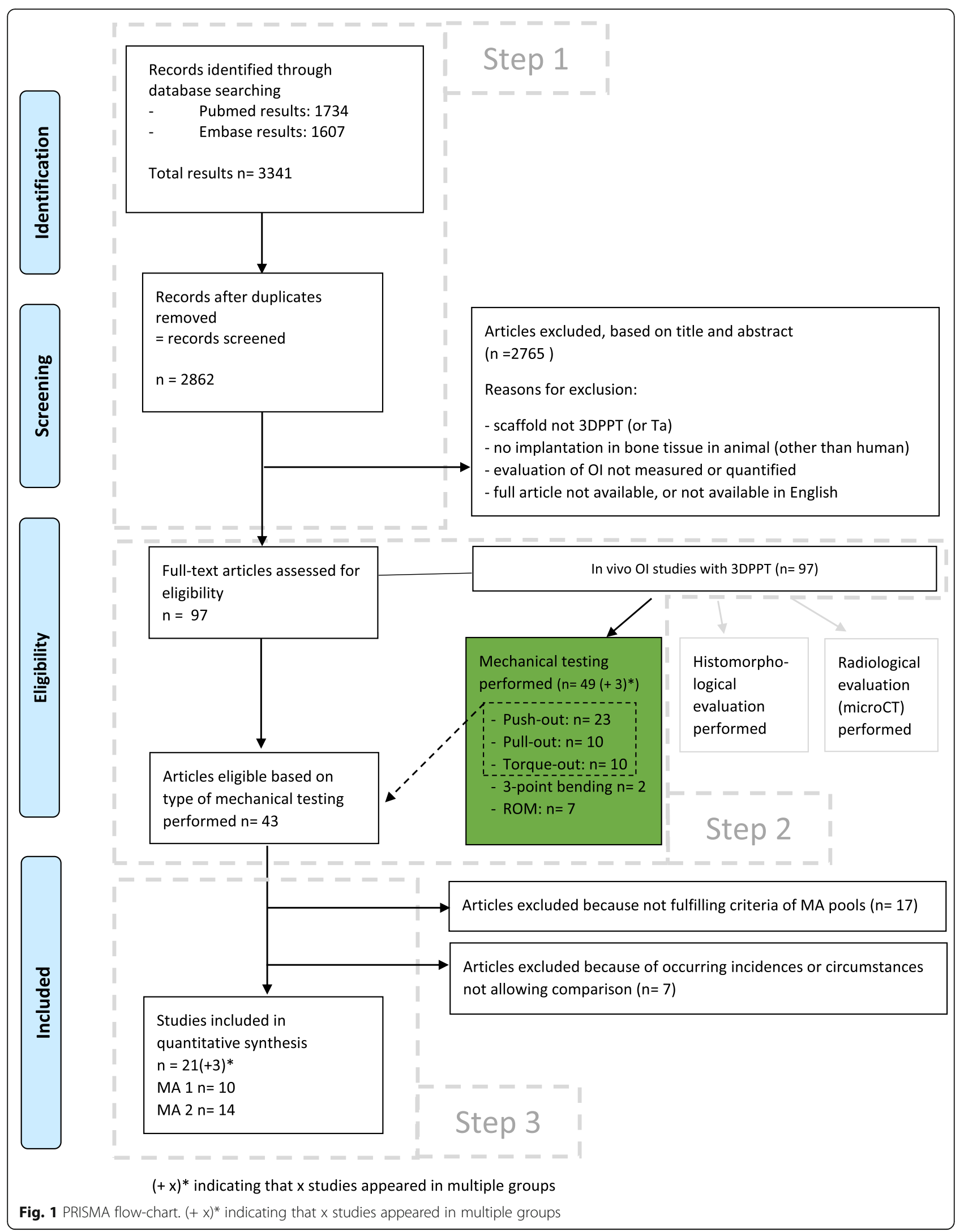


Data extraction allowed the allocation of 26 articles among two MA pools, and further narrowing (to obtain truly comparable groups of studies) brought the total to 10 studies in MA1 [5-14] (providing 32 observations) and 14 studies in MA2 [7-9, 15-24] (providing 40 observations). Three studies were included in both MAs [7-9].

\section{Study characteristics}

The study characteristics included in MA1 and MA2 are listed in Tables 2 and 3. We included different animal models [rat, rabbit (regular and osteoporotic OVX), dog, and sheep], with sample sizes between 2 and 12 and follow-up periods between 2 weeks and 6 months. Almost all the studies used a trabecular bone model (femur condyle, pelvis, and tibia), except for [8], which used a cortical (calvaria onlay) model (with perforations of the bone at the implantation site). The implants were most often regular and cylindrical (otherwise screw, prism, or block shaped) with reported dimensions, allowing the calculation of the shear surface (A). The implant reported by Amin Yavari et al. was irregularly shaped but was included because the bone-implant contact surface of this construct was a clearly defined circle, which corresponded to the shear surface during the performed torque-out testing [15]. The study reported by $\mathrm{Xu}$ et al. was approached similarly because the implant was cupshaped but with a clearly defined circle as the bonecontact surface, corresponding to the shear surface during pull-out testing [21].

\section{Quality of research}

The results of the ROB evaluation are shown in Fig. 2. Our studies showed only few actual predispositions toward bias (namely one case of selective reporting [12]). Furthermore, eight studies mentioned financial support of industry partners. In general, "random sequence generation", "blinding of personnel", and "allocation concealment" were poorly reported, causing uncertainty. Most publications mentioned institutional approval of study protocols and concordance to institutional guidelines concerning animal use and care.

\section{Results of quantitative synthesis}

The studies included in MA1 were all very small and showed considerable heterogeneity $\left(\mathrm{I}^{2}=76.3 \%\right.$; i.e., the percentage of variability in ES not caused by sampling error). Thus, we applied a mixed-effects model, which offered a between-study variance estimate $\left(\tau^{2}\right)$ of 3.0710 (CI $[1.3639 ; 5.8734]$ ) and estimated the SMD (of the shear strength of the bone-titanium interface between the 3DPPT and dense Ti groups) to be $2.79(p<0.0001$ and CI $[2.0613 ; 3.5090])$. The forest plot of MA1 is displayed in. $3 \mathrm{a}$ and shows that most of the studies have a positive TE with widespread overlap in CIs. Removing statistical outliers from the MA (a total of 6 observations, for which the CIs did not lie within the CI of the pooled effect) elevated the SMD to 3.39 (and lowered the $\mathrm{I}^{2}$ to 24). However, because there was no evidence that these study results were invalid for our study, we did not exclude these outliers. Figure $3 b$ shows the funnel plot of MA1, displaying noticeable asymmetry (with confirmation by Egger's test).

To extend this MA to a meta-regression, we first conducted an exploratory AICc-based ranking of moderators but ultimately performed step-down selection based on the offering of a significant $p$-value for the test of moderators. Our final (most appropriate) model only included the predictor "animal type" as the independent variable [test of moderators $\mathrm{F}(\mathrm{df} 1=2, \mathrm{df} 2=293.8722)$, $\left.p=0.0323, R^{2}=33.24 \%\right]$. In this model, the regression coefficient (RC) for the animal type "rabbit" was estimated to be 2.7 times higher than for the "rat" model (intercept $=5.6009$ ) and the "sheep" model was estimated to be 4.7 times lower. These findings are shown in Fig. 3c. Extending this model to multivariable metaregression by adding "pore-size" as a covariable also yielded a significant $p$-value for the test of moderators [F $(\mathrm{df} 1=3, \mathrm{df} 2=28)=3.0419, p=0.0453]$ as well as that of a model involving the interaction of "pore-size" and "animal type" $[\mathrm{F} \quad(\mathrm{df} 1=5, \mathrm{df} 2=26)=2.8876, \quad p=0.0333]$. These combinations raised the accounted heterogeneities $\left(R^{2}\right)$ to 38.55 and $52.78 \%$, respectively. However, the likelihood ratio test comparing all three models found no superiority of the extended models; thus, the simpler "animal type only" model was favored. To offer a better understanding of their relationship, Fig. $3 \mathrm{~d}$ shows the TE of all observations in MA1 as a function of the variable "pore-size" reported in the study.

Because "rabbit" was our most represented model, we performed subgroup analysis to exclude the aforementioned effect of "animal type" and further investigate the role of other possible moderators. Here, a multivariable regression model with the interaction of covariables "pore-size" and "porosity" provided the most significant $p$-value $(p=0.0130)$ for the test of moderators [F ( df1 = $3, \mathrm{df} 2=15)=5.0371]$, with the likelihood ratio test favoring it over a reduced "pore-size only" or "pore-size and porosity but no-interaction" model. We noted that "pore-size" and "porosity" were correlated (0.79), making it impossible to fully distinguish between both. This model accounted for $66.44 \%$ of the heterogeneity (R2) and $\mathrm{RC}=-0.0022 \quad[p=0.0803$ (not significant, but strongly associated)]. This finding is illustrated in Fig. 3e, which shows a coplot of the covariates "pore-size" and "porosity".

MA2 showed a similar, moderately high heterogeneity $\left(\mathrm{I}^{2}=72.2 \%\right)$ and a between-study variance $\left(\mathrm{\tau}^{2}\right)$ of 3.8944 


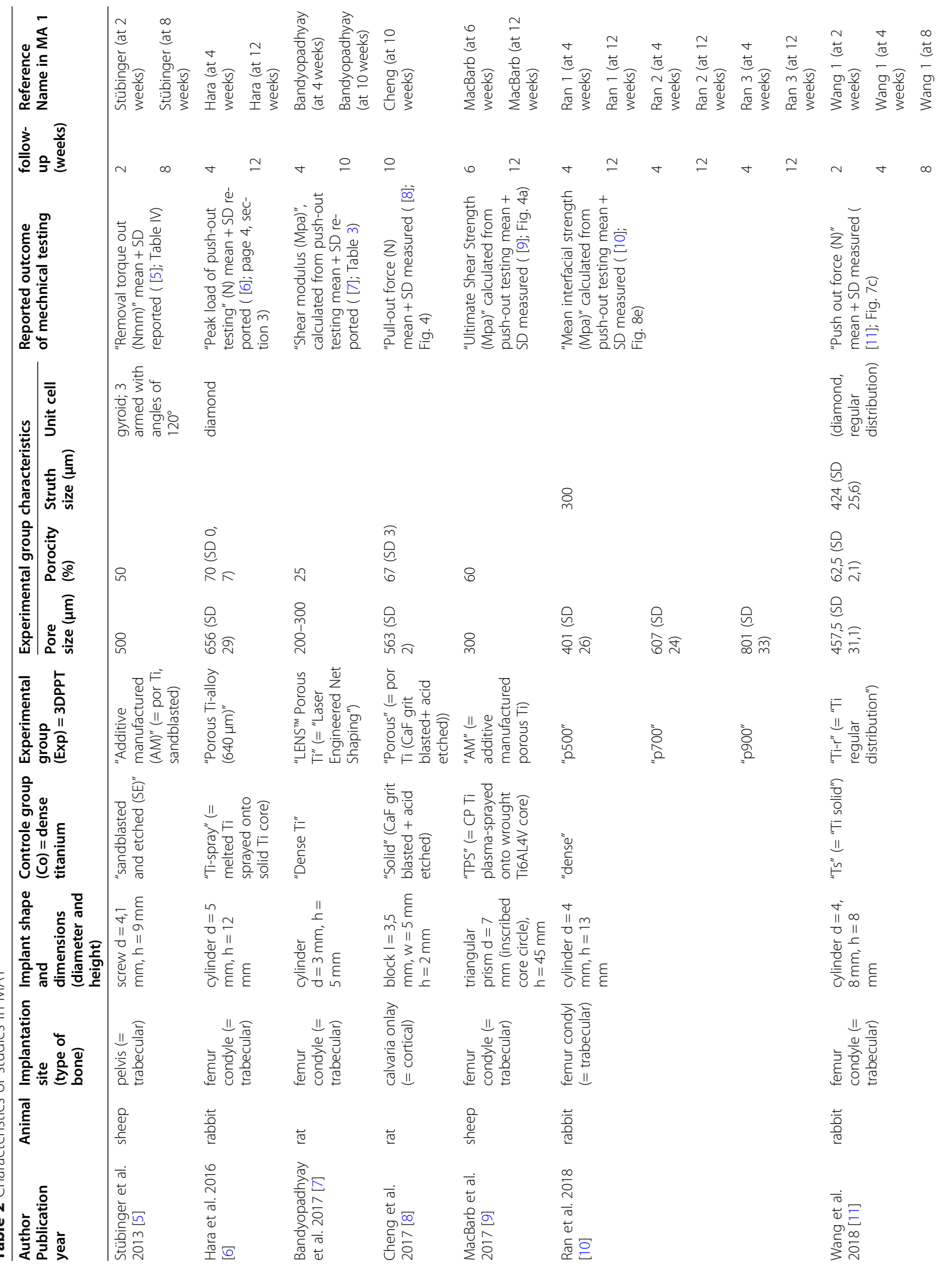




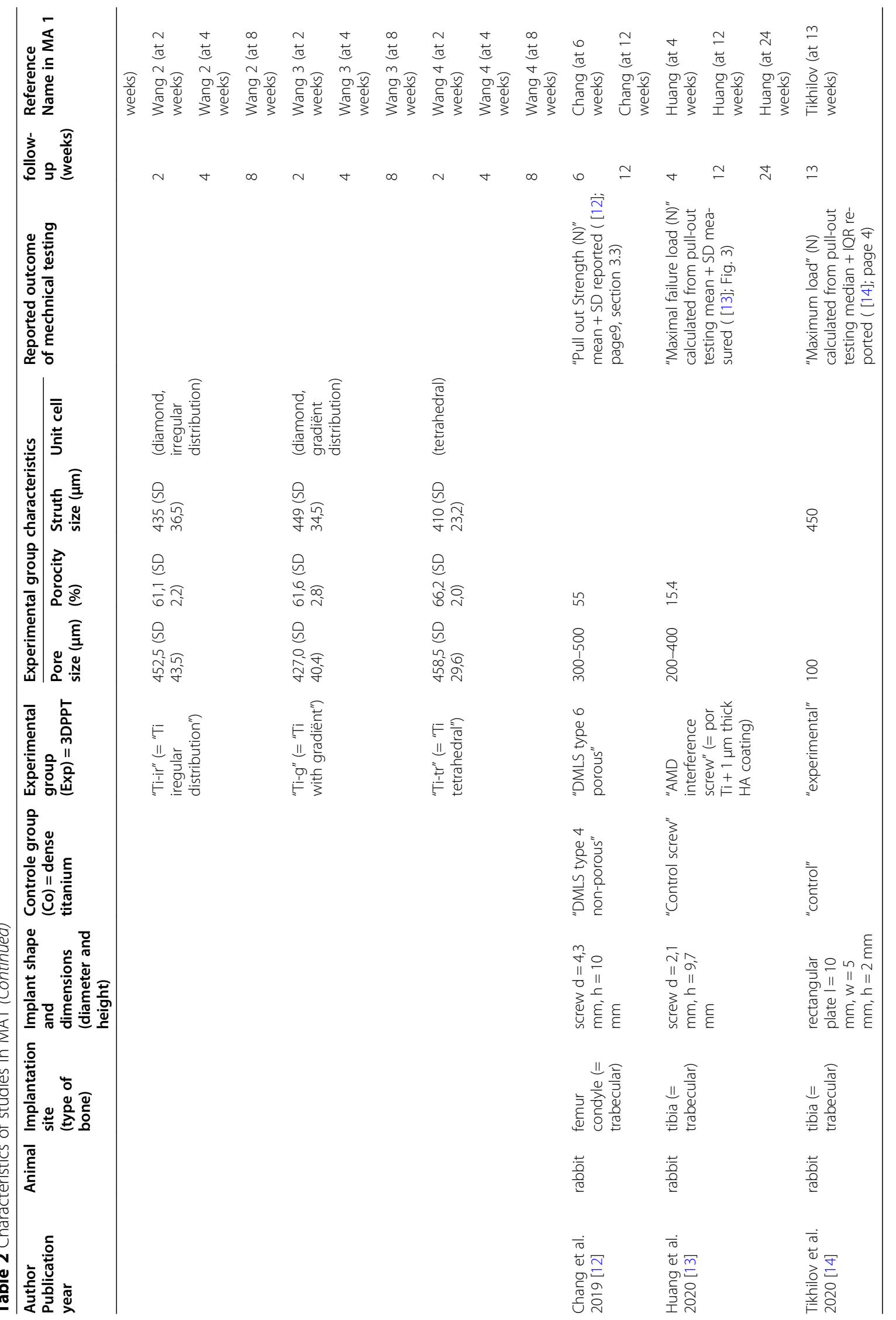




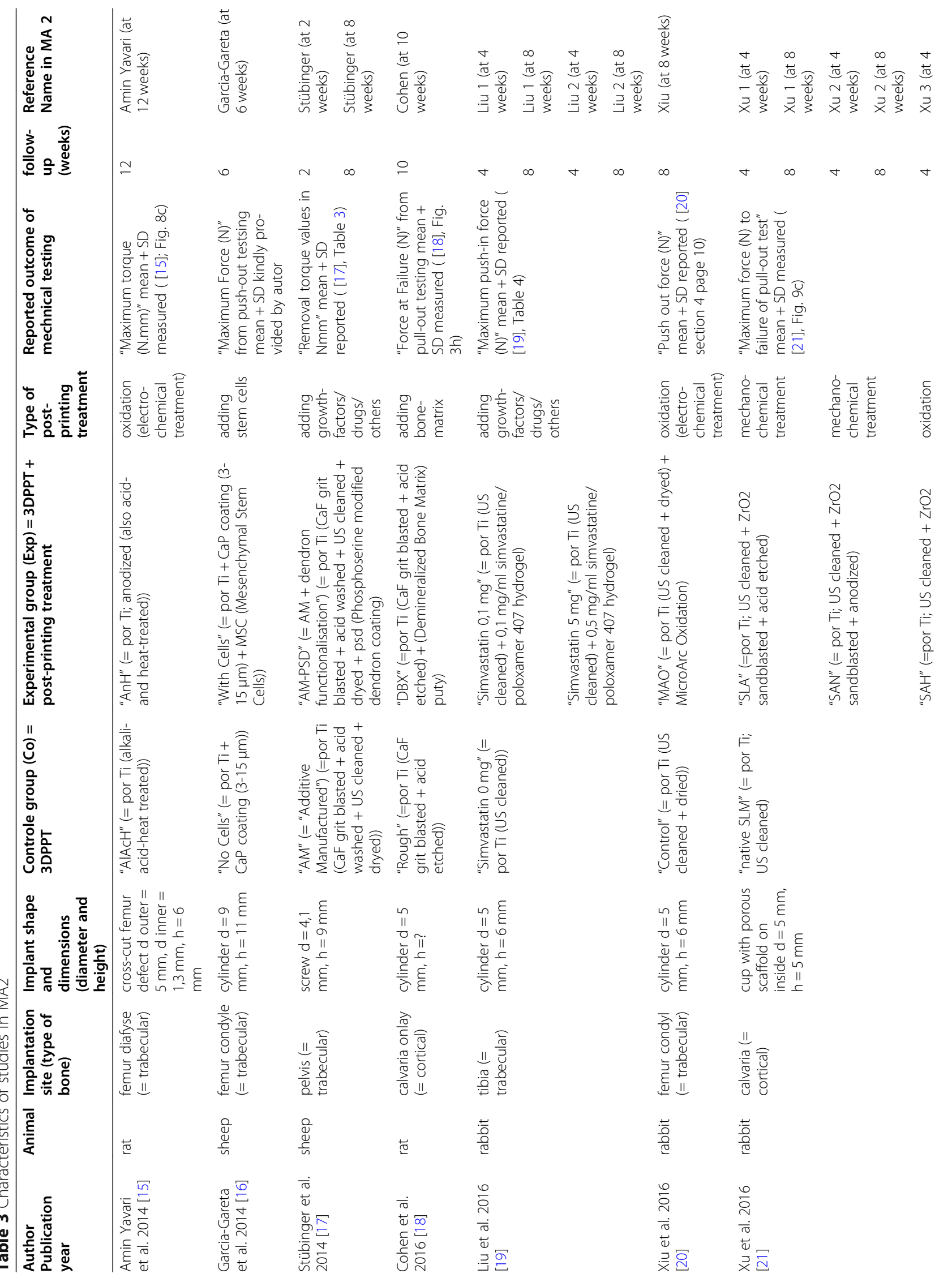




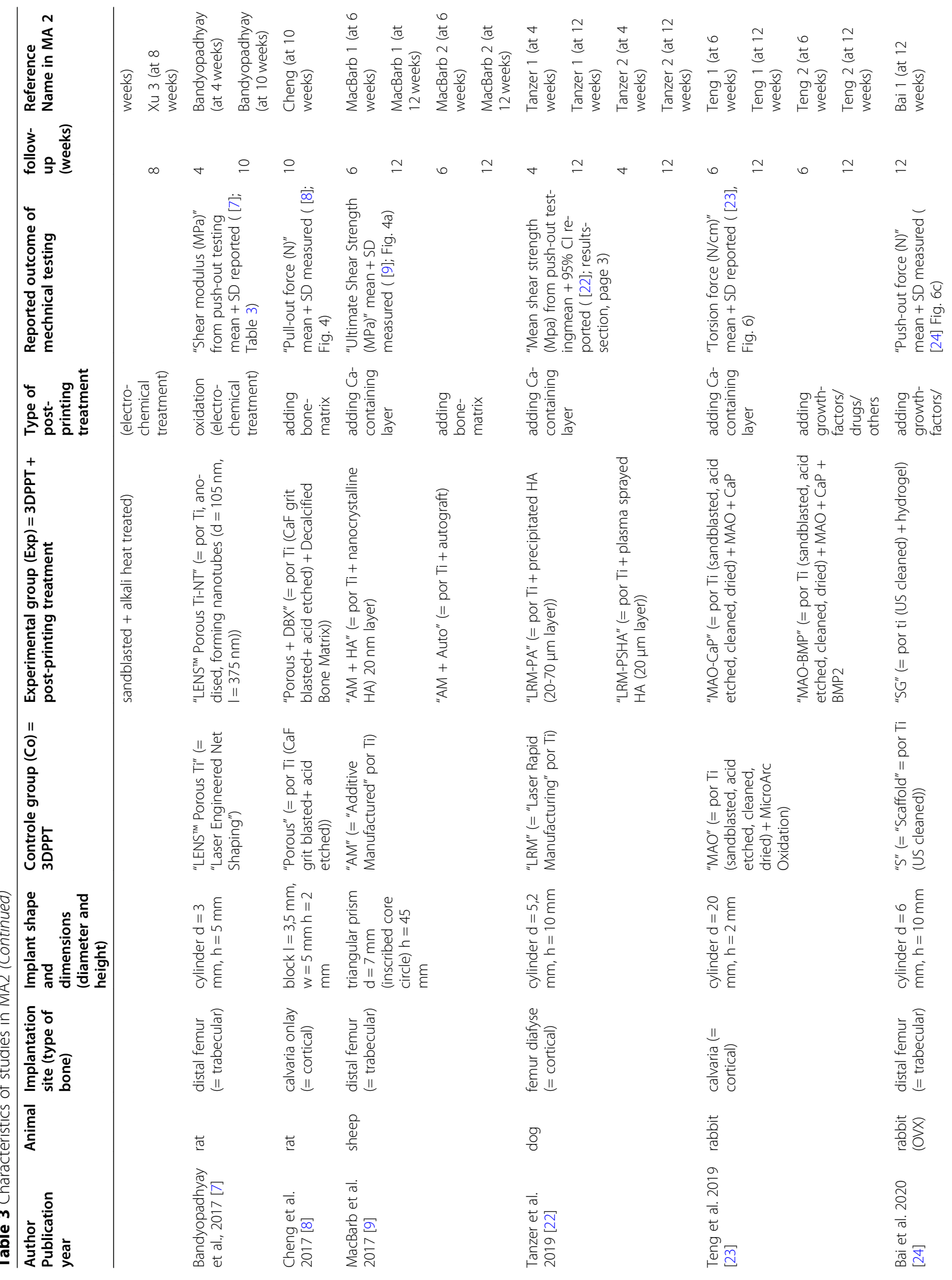




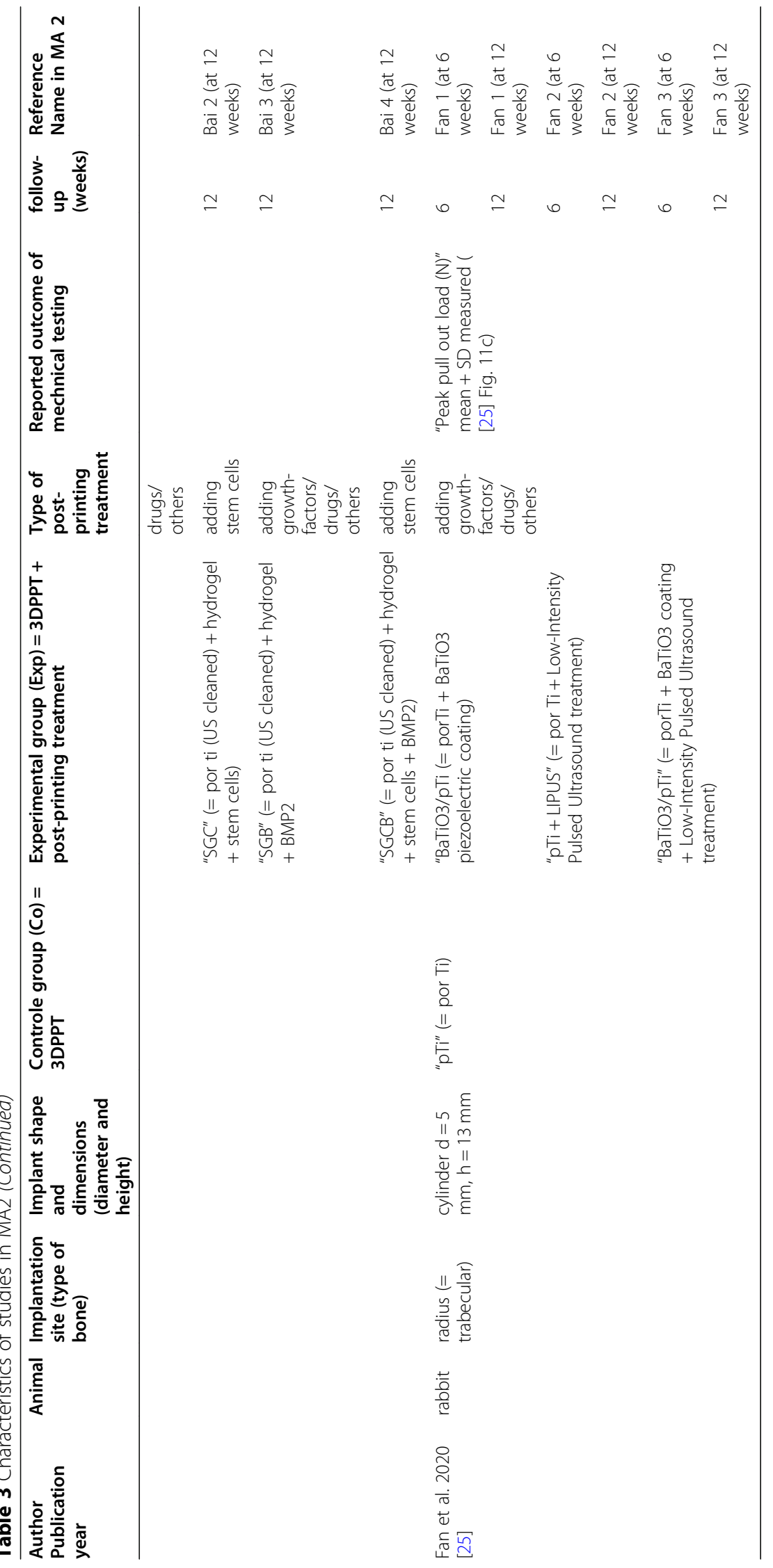




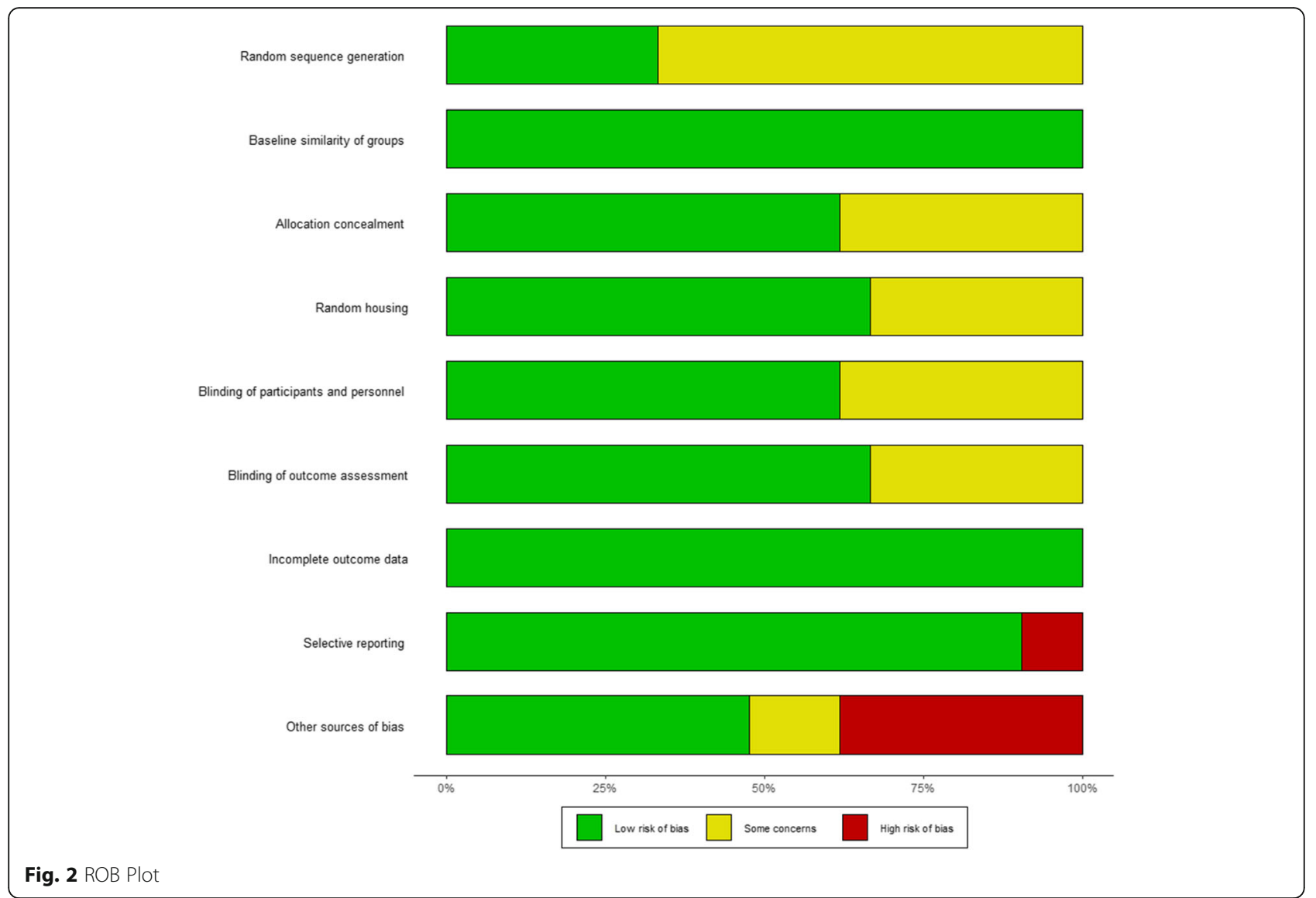

(CI[1.5477; 6.5609]) for which a mixed-effects model was applied again. The data, in turn, provided an SMD of $1.63(p<0.0001$, CI [0.9612; 2.2975], PI [-2.4212; 5.6799]). The forest plot of MA2 is shown in Fig. 4a and shows even greater overlap in CIs than that of MA1. Removing outliers [10] would have lowered $\mathrm{I}^{2}$ to $36.6 \%$ and kept the SMD at 1.64 (while narrowing the $\mathrm{CI}$ to [1.2036; 2.0893]. However, we excluded this procedure because we had no evidence that these study results did not affect our studies. Similar to MA1, MA2 showed noticeable funnel plot asymmetry, displayed in Fig. 4b.

Regarding MA2, we included the single moderator "treatment type" to provide the model with the best $p$ value for the test of moderators $(\mathrm{F}(\mathrm{df} 1=5, \mathrm{df} 2=34)=$ 2.5932, $p=0.0432$ ). The likelihood ratio test favored this model over a combined "animal type and treatment type" model, and it provided an $\mathrm{R}^{2}$ of $44.58 \%$. The RCs for the individual "treatment types" were not significant.

\section{Discussion}

Many reports have been published concerning 3DPPT $[6,9,12,14,25]$, and reviews have revealed the difficulty of decision making based on the interpretation of this information [26-28]. Publications attempting to provide an overview almost always rely on either a biomimetic approach (3DPPT printed so that the lattice provides an optimized mechanical and biological match to bone tissue) or optimal printability/producibility. When 3DPPT is approached from this biomimetic starting point, ellipsoidal pores of $300-600 \mu \mathrm{m}$ should match cancellous bone and cylindrical canals of pore-size $10-50 \mu \mathrm{m}$ should match cortical bone [29]. The porosities of cancellous and cortical bone are 50-90\% and 3-10\%, respectively. However, in 3DPPT, "porosity" is more often approached as the parameter to adjust the Young's modulus and is varied in the function of desired mechanical stiffness. A recent review by Martinez-Marquez et al. on experimental 3DPPT research reported the three most used types of unit cells as "diamond", "gyroid TPMS", and "cubic", with $56.6 \%$ of studies using a porosity of $30-70 \%$ and $86.8 \%$ applying pore sizes between 100 and $1000 \mu \mathrm{m}$ [29]. Some studies experimenting within these ranges have stated that, for cell ingrowth, a $100-\mu \mathrm{m}$ pore-size diameter would be a minimum value; for vascular invasion and the formation of capillaries, this value would more likely be approximately $300 \mu \mathrm{m}$ [12]. The ideal ranges for OI are most often defined between 200 and $400 \mu \mathrm{m}$ [9] and 50-400 $\mu \mathrm{m}$ for soft-tissue integration [14]. Larger diameters would permit better initial cell migration and nutrient diffusion but rapidly 


\section{a}

study

Experimental
Total Mean SD Total Mean ${ }^{\text {Control }}$ SD

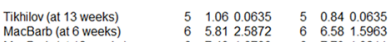

MacBarb (at 12 wee
Ran 1 (at 4 weeks)

Ran 1 (at 12 weets

Wang 3 (at 4 we
Wang 3 at 8 we

Wang 2 (at 2 we

Wang 2 (at 8 (at 2 week
Wang 1 (at 4 week

Wang 1 (at 8 wee
Wang 4 (at 2 wee

Wang 4 (at 8 weeks

Stubinger (at 2 weeks
Stubinger lat 8 weeks

Ran 2 (at 4 weeks)
Ran 2 (at 12 weeks)

Hara (at 4 weeks
Hara (at 12 weels)

Ran 3 (at 4 weeks)
Ran 3 (at 12 weeks)

Bandyopadhyay (at 4
Huang (at 4 weeks)
Huang (at 12 weeks)

Huang (at 24 weeks)
Chang (at 6 weeks)

Chang (at 6 weeks)
Chang (at 12 weeks)

Random effects model 177

Prediction interval

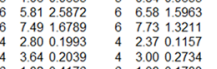

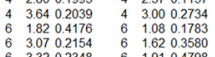

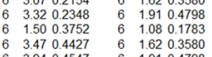

$\begin{array}{lllll}6 & 3.47 & 0.42727 & 6 & 1.620 .3580 \\ 6 & 3.940 .4547 & 6 & 1.91 & 0.04798 \\ 6 & 101 & 2074 & 6 & 10807783\end{array}$

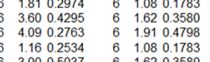

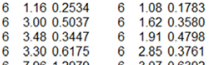

$\begin{array}{lllll}6 & 3.30 & 0.6175 & 6 & 2.850 .3761 \\ 6 & 7.961 .2979 & 6 & 3.07 & 0.6392 \\ 8 & 0.880 .1120 & 8 & 0.340 .0576 \\ 4 & 3.200 .2966 & 4 & 2.37 & 0.1157 \\ 4 & 4 & 0.2960 & \end{array}$

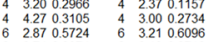

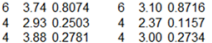

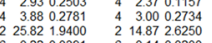

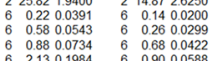

$\begin{array}{llllll}6 & 0.88 & 0.0734 & 6 & 0.68 & 0.0422 \\ 6 & 2.13 & 0.1984 & 6 & 0.90 & 0.0588 \\ 6 & 2.23 & 0.2131 & 6 & 0.96 & 0.1029\end{array}$

177

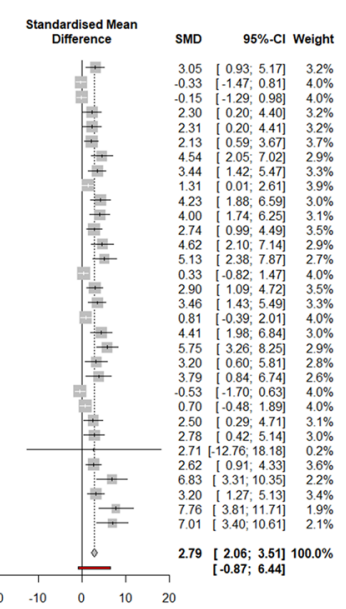

C

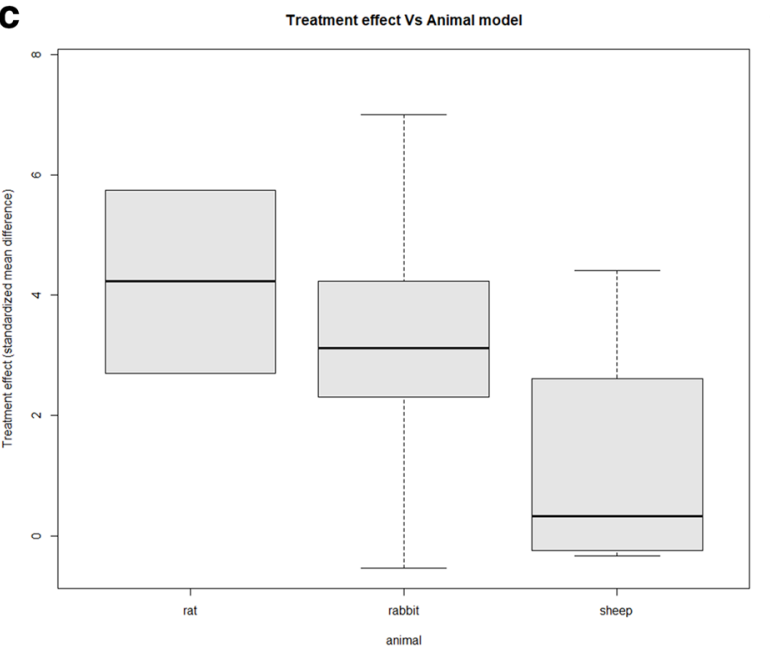

d

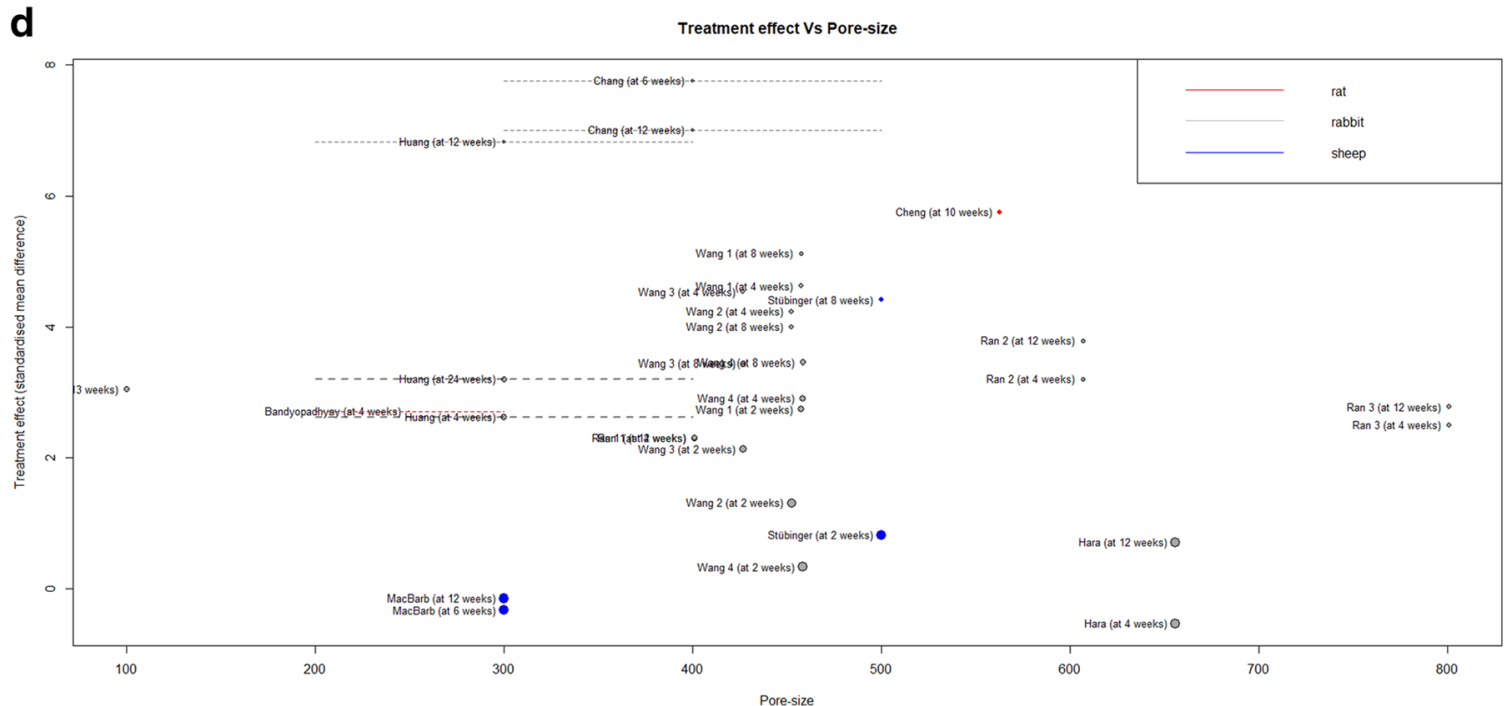

b

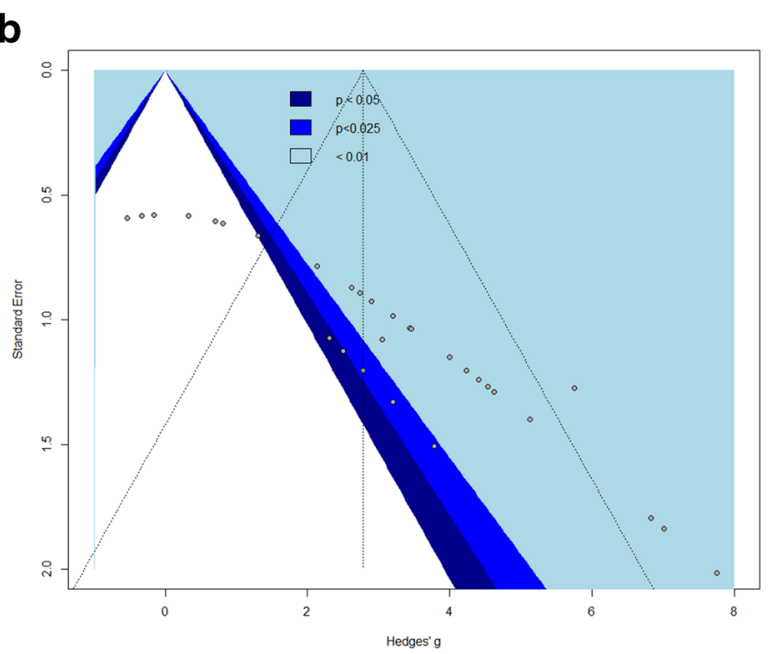

e
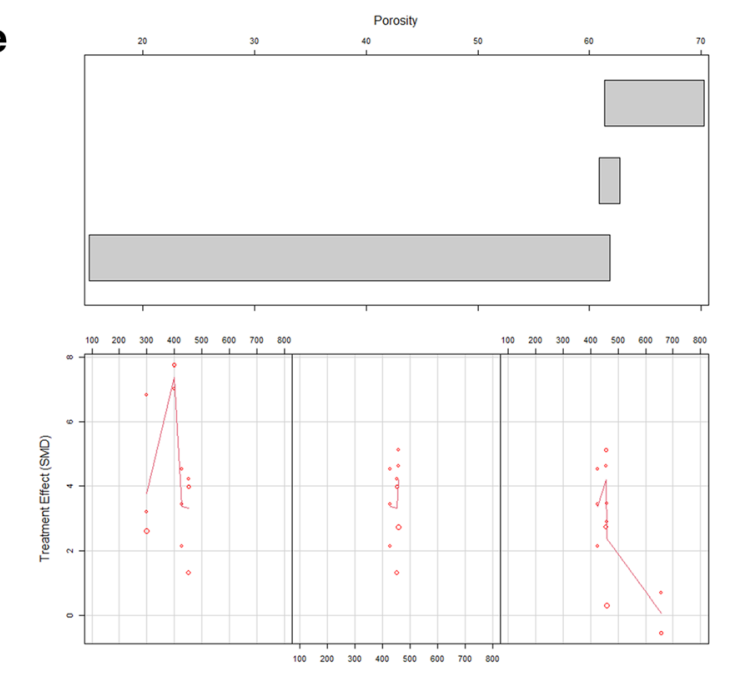

Pore-size 
(See figure on previous page.)

Fig. 3 Graphics from MA1: a Forest plot displaying included studies and calculated treatment effects (SMD). b Funnel plot displaying publication bias. c Regression model of moderator analysis 1 showing the relationship between the treatment effect and the moderator "animal type". $\mathbf{d}$ Pore-sizes of all the studies included in MA1 (weighted with the inverse of their variance for their size, represented with a dotted line in the case of the reported pore-size range) vs. their corresponding calculated TE. e Coplot displaying pore-sizes of all the studies included in the rabbit subgroup analysis vs. their corresponding TE (SMD) (below), but allocated to three graphs, corresponding to three clusters of porosity values (above)

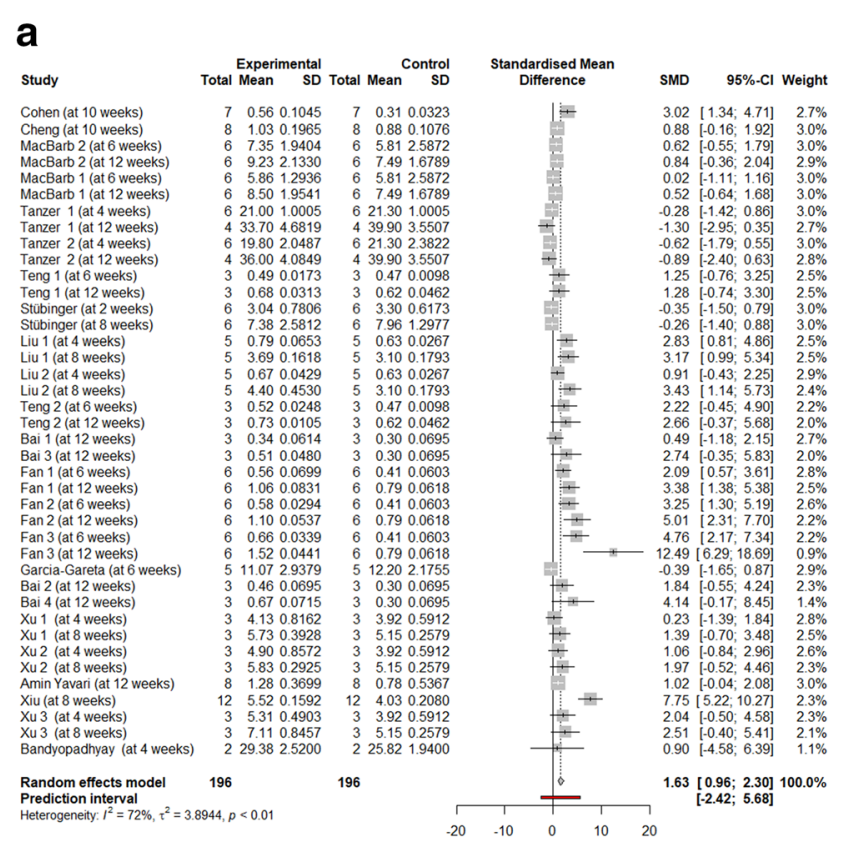

\section{b}

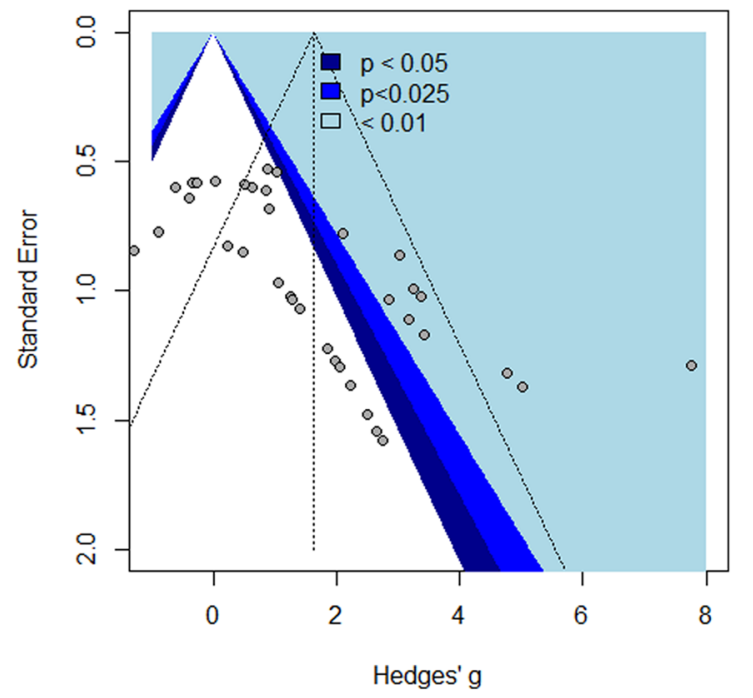

C

Treatment Effect Vs Type of Treatment

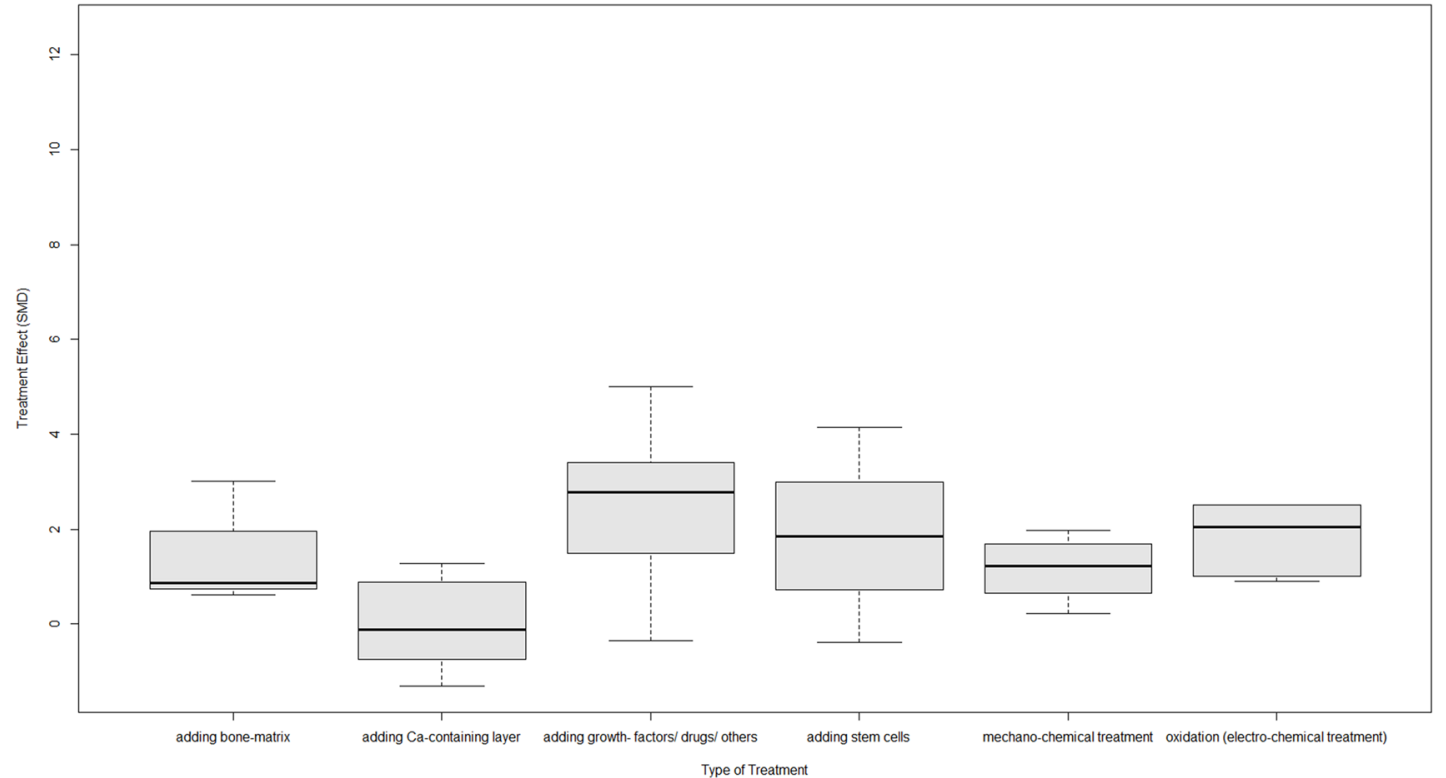

Fig. 4 Graphics from MA2: a Forest plot displaying the included studies and calculated treatment effects (SMD). b Funnel plot displaying publication bias. $\mathbf{c}$ Regression model of moderator analysis 2 showing the relationship between the treatment effect and the moderator "type of treatment" 
diminish mechanical strength [25]. Studies then comparing different pore sizes at a set porosity have found superior pull-out strength of pore-size $600 \mu \mathrm{m}$ over $300 \mu \mathrm{m}$ and $900 \mu \mathrm{m}$ in rabbits at a 2-week observation point [30]. Wang et al. used implants with similar pore sizes, Struth sizes and porosities but varying distributions and configurations of unit cells and found no significant differences in the pullout strength in rabbits at either time point [11]. Li et al. also confirmed these findings, applying gradients of pore sizes $300-500 \mu \mathrm{m}, 200$ $600 \mu \mathrm{m}$, and $100-700 \mu \mathrm{m}$ for a 5 -week observation in mini-pigs [25].

Here, we conducted an SR and 2 separate MAs. The SMDs calculated (2.79 for MA1 and 1.63 for MA2) were not the focus of our search. They express a difference in the mechanical removal strength between porous and non-porous 3D-printed titanium implants and between post-treated and non-post-treated 3DPPT implants, expressed as the difference in the of SDs of TE; these differences are reasonable and have never been challenged, particularly concerning the former. However, the asymmetry in the funnel plots (Figs. $3 \mathrm{~b}$ and $4 \mathrm{~b}$ ) should temper these assumptions. Because the funnel plots display a negative, almost linear regression between the standard error (SE) and treatment effect (TE) (i.e., large treatment effects are reported by less precise (smaller) studies, while more reliable (large) studies show little to no TE), it appears that the results of our MAs show evidence of publication bias.

In MA1, we found that the "animal model" as a moderator may explain a difference in TE. Because our TE indicates improvement in the mechanical removal strength when making the implants porous vs not porous, less improvement is expected when implanting a porous implant in a sheep than in a rat. For the rabbit model, we had many more observations than those for rats or sheep (26/32 observations), and the TE values enclosed a wider reach (Fig. 3d; observations in gray). Here, the best fitting model involved the interaction of "porosity" and "pore-size". The strong relationship between these covariables (correlation coefficient of approximately 0.8 ) reflects that these factors may not be fully distinguishable characteristics of the included studies [31]. Regarding content and in a context of 3DPPT, the influence of "pore-size" on mechanical removal strength should be investigated considering the number of pores. Thus, we included "porosity" to represent this measure, although it is more accurately a measure of the porous volume fraction; our MAs do not allow us to derive an accurate estimate of the number of pores for each lattice reported. For the actual representation of these covariables, we used a coplot, displaying the regression-lines of "pore-size" to "TE" at three corresponding (but overlapping) ranges of "porosity" (Fig. 3e).
In summary, the three curves formed describe the following: 1) an ascent, with a peak at a "pore-size $400 \mu \mathrm{m}$ " and then a decline in the TE of implants with a "poresize" of 300-500 $\mu \mathrm{m}$ and a "porosity" of $15-61.6 \%$; 2) a slight decline and again sharp ascent in the TE of implants with a "pore-size" of 400-500 $\mu \mathrm{m}$ and a "porosity" of 61.1-66.2\%; and 3) a small peak, rapid decline at a "pore-size" of 400-500 $\mu \mathrm{m}$ and a slower decline (reaching $\mathrm{TE}=0$ ) at a "pore-size" $>500 \mu \mathrm{m}$ and a "porosity" of $62.5-70 \%$. Our study found the highest TE at a pore size of $400 \mu \mathrm{m}$ and a porosity of 55\%; however, considering precision, it is likely safer to conclude that a pore-size of $300-450 \mu \mathrm{m}$, with a porosity of $50-65 \%$, consistently shows improved OI (Fig. 3e), at least in a rabbit model. We have no observations at less than $300 \mu \mathrm{m}$ but observed a decline at greater than $450 \mu \mathrm{m}$. Literature describing tested animal models states that the bone microanatomy of rabbits and sheep differ from that of the humans and also from each other; for example, the average diameter of the long bone trabecula of sheep is less than $100 \mu \mathrm{m}$ and that of rabbits is $50-220 \mu \mathrm{m}$ [32]. Walsh et al. [33] observed significantly more bone ingrowth in 3DPPT implanted in a cortical sheep tibia model than in a trabecular femur model, indicating that the implantation site might be important for OI. GarciaGareta et al. [16] also noticed a reduced push-out strength of 3DPPT implanted in a sheep gap model vs. a press-fitted model (regardless of the addition of stem cells). However, to our knowledge, no study has explored differences in the mechanical strength of the OI of 3DPPT using scaffold parameters more closely adjusted to the animal (bone) type or implantation site.

In MA2, the only significant moderator was "type of treatment", which showed that the treatments comprising adding a Ca-containing layer had a significantly lower TE than the other treatment types. This finding is likely controversial because the beneficial effect of these types of coatings (CaP, hydroxy-apatite) on the bonetitanium interface strength of solid titanium is well established [34-37]. A possible explanation could be sought for the supposed pore-filling effect of the $\mathrm{Ca}$ containing layer that might negatively affect the mechanical bone-titanium interface in short-term evaluations. Because these $\mathrm{Ca}$-containing layers are biodegradable and diminish over time, a supposed changed influence over time (exceeding the 6-month maximum span of our reported studies) might also be worth exploring.

However, because certain caveats apply to our study, our findings should be interpreted with caution. First, substantial heterogeneity was found among the included studies, as demonstrated by the high $\mathrm{I}^{2}$ values. An explanation could be the discrepancy between grouping different animal models at the MA level and extreme genetic similarity of the individual animals at the study 
level [4]. The Cochran $Q$ value in the rabbit subgroup analysis was lower $(85 ; p<0.0001)$ but still significant. The SMDs from MA1 and MA2 both show high betweenstudy variance values, indicating that the estimated effects differ across studies. Another explanation could be an overlooked effect due to variation in the observation methods (i.e., non-correspondence of pull-out, push-out, and torque-out testing). However, because the included studies were small (12 samples at best), there is no straightforward explanation for the heterogeneity and we should conclude that both MAs are sensitive to biasing animalities [38]. Second, our allocation of studies between the two MA pools is debatable. In MA1, in the study of Huang et al., the Exp group was porous but also HA coated (1- $\mu \mathrm{m}$ thick) [13]. However, our study considered $1 \mu \mathrm{m}$ as a thin layer [36]. In MA2, the allocation of "similar types of post-treatment" into six categories could not be performed completely unambiguously because some studies had characteristics compatible with multiple categories [24]. Third, because MA1 and 2 comprised sample sizes of 177 and 196 animals in 32 and 40 observations, respectively, we had sufficient samples to perform MAs. With this level of observation, applying models with up to two predictors and an interaction effect is considered a valid practice [4]. However, multivariable meta-regression of the rabbit subgroup analysis was based on only 19 observations, which might be at the lower limit of what is acceptable [4]. A full comparison of all forementioned moderators was restricted to only 12 observations (studies always reported "pore-size", and most often only "porosity" or "Struth-size", seldomly both, and many authors did not respond to our requests for extra specification). The final caveat, though obvious, would be not to confuse statistical associations for causality.

\section{Conclusion}

We performed two separate MAs with moderator analyses to determine whether statistical models including reported scaffold features ("pore-size", "porosity", and" type of unit cell") or post-printing treatments (adding stem cells, growth factors, drugs, and surface treatments) could explain the observed differences in the treatment effect. Our findings suggest a stronger effect from porosity in a rat model than that in a sheep model. Additionally, adding a calcium-containing layer does not improve the mechanical removal strength but the other post-treatment types do. Our results provide an overview and some new insights but little narrowing of the existing value ranges. We would advocate more research involving comparing implantation to similar, "standardized" control groups and expressing "pore-size" and "porosity" in terms of surface roughness to help address existing dilemmas, along with the consequent reporting of 3DPPT characteristics.

\section{Abbreviations}

Ti: Titanium; Ta: Tantalum; Ca: Calcium; n: Number; 3DPPT: 3D-Printed, Porous Titanium; OI: Osteointegration; SR: Systematic Review; MA: Meta-Analysis; ROM: Range of Motion; Exp: Experimental Group; Co: Control Group; SD: Standard Deviation; SMD: Standardized Mean Differences; Cl: 95\% Confidence Interval; $\tau^{2}$ : Between-study Variance; PI: Prediction Interval; OVX: Ovariectomy; TE: Treatment Effect; ROB: Risk of Bias

\section{Acknowledgements}

The authors wish to thank Thomas Vandendriessche, Kristel Paque, and Krizia Tuand, the biomedical reference librarians of the KU Leuven Libraries -

2Bergen - Learning Centre Désiré Collen (Leuven, Belgium), for their help in conducting the systematic literature search.

\section{Authors' contributions}

All authors contributed to the concept of this review. SC and RC performed the literature search, selection and acquisition of data. SC, SH and WC performed statistical analysis and interpretation. SH provided statistical software support (wrote scripts in R studio). The original draft was written by SC. Reviewing and editing was done by MM and WC. The author(s) read and approved the final manuscript.

\section{Funding}

This research received no specific grant from funding agencies in the public, commercial, or not-for-profit sectors.

\section{Availability of data and materials}

The datasets used and/or analyzed during the current study are available from the corresponding author on reasonable request.

\section{Declarations}

Ethics approval and consent to participate

Our review did not perform animal testing, but reported on animal testing performed by others.

All references involving animal testing reported approval by an ethics committee.

\section{Consent for publication}

Not applicable.

\section{Competing interests}

The authors declare that they have no competing interests.

\section{Author details}

${ }^{1}$ Doctoral School of Life Sciences and Medicine, Vrije Universiteit Brussel, 1090 Brussels, Belgium. European Face Centre, Universitair Ziekenhuis Brussel, Vrije Universiteit Brussel, 1090 Brussels, Belgium. ${ }^{3}$ Engineering Science, Department of Mechanical Engineering, Section of Biomechanics, Catholic University of Leuven, 3000 Leuven, Belgium. ${ }^{4}$ Interfaculty Center Data processing and Statistics, Vrije Universiteit Brussel, 1090 Brussels, Belgium.

Received: 28 February 2021 Accepted: 15 April 2021

Published online: 10 June 2021

\section{References}

1. Diamanti MV, Del Curto B, Pedeferri M. Anodic oxidation of titanium: from technical aspects to biomedical applications. J Appl Biomater Biomech. 2011;9(1):55-69. https://doi.org/10.5301/JABB.2011.7429.

2. Chen L, Guo X, Li Y, Li T. Finite element analysis for interfacial stress and fatigue behaviors of biomimetic titanium implant under static and dynamic loading conditions. Zhong Nan Da Xue Xue Bao Yi Xue Ban. 2010;35(7):66272. https://doi.org/10.3969/j.issn.1672-7347.2010.07.004.

3. Murr LE, Gaytan SM, Medina F, Lopez H, Martinez E, Machado BI, et al. Nextgeneration biomedical implants using additive manufacturing of complex, cellular and functional mesh arrays. Philos Trans A Math Phys Eng Sci. 2010; 368(1917):1999-2032. https://doi.org/10.1098/rsta.2010.0010.

4. Vesterinen HM, Sena ES, Egan KJ, Hirst TC, Churolov L, Currie GL, et al. Metaanalysis of data from animal studies: a practical guide. J Neurosci Methods. 2014;221:92-102. https://doi.org/10.1016/j.jneumeth.2013.09.010. 
5. Stubinger S, Mosch I, Robotti P, Sidler M, Klein K, Ferguson SJ, et al. Histological and biomechanical analysis of porous additive manufactured implants made by direct metal laser sintering: a pilot study in sheep. J Biomed Mater Res B Appl Biomater. 2013;101(7):1154-63. https://doi.org/1 0.1002/jbm.b.32925.

6. Hara D, Nakashima Y, Sato T, Hirata M, Kanazawa M, Kohno Y, et al. Bone bonding strength of diamond-structured porous titanium-alloy implants manufactured using the electron beam-melting technique. Mater Sci Eng C Mater Biol Appl. 2016;59:1047-52. https://doi.org/10.1016/j.msec.2015.11.025.

7. Bandyopadhyay A, Shivaram A, Tarafder S, Sahasrabudhe H, Banerjee D, Bose S. In vivo response of laser processed porous titanium implants for load-bearing implants. Ann Biomed Eng. 2017;45(1):249-60. https://doi.org/1 0.1007/s10439-016-1673-8.

8. Cheng A, Cohen DJ, Kahn A, Clohessy RM, Sahingur K, Newton JB, et al. Laser sintered porous Ti-6Al-4V implants stimulate vertical bone growth. Ann Biomed Eng. 2017;45(8):2025-35. https://doi.org/10.1007/s10439-017-1 831-7.

9. MacBarb RF, Lindsey DP, Woods SA, Lalor PA, Gundanna MI, Yerby SA. Fortifying the bone-implant Interface part 2: an in vivo evaluation of 3Dprinted and TPS-coated triangular implants. Int J Spine Surg. 2017;11(3):16. https://doi.org/10.14444/4016.

10. Ran Q, Yang W, Hu Y, Shen X, Yu Y, Xiang Y, et al. Osteogenesis of 3D printed porous Ti6Al4V implants with different pore sizes. J Mech Behav Biomed Mater. 2018;84:1-11. https://doi.org/10.1016/j.jmbbm.2018.04.010.

11. Wang H, Su K, Su L, Liang P, Ji P, Wang C. The effect of 3D-printed Ti6Al4V scaffolds with various macropore structures on osteointegration and osteogenesis: a biomechanical evaluation. J Mech Behav Biomed Mater. 2018;88:488-96. https://doi.org/10.1016/j.jmbbm.2018.08.049.

12. Chang JZ, Tsai PI, Kuo MY, Sun JS, Chen SY, Shen HH. Augmentation of DMLS BiomimeticDental Implants with Weight-Bearing Strut to Balance of Biologic and Mechanical Demands: From Bench to Animal. Materials (Basel). 2019:12(1):164.

13. Huang YM, Huang CC, Tsai PI, Yang KY, Huang SI, Shen HH, et al. ThreeDimensional PrintedPorous Titanium Screw with Bioactive Surface Modification for Bone-Tendon Healing: A Rabbit Animal Model. Int J Mol Sci. 2020:21(10):3628.

14. Tikhilov R, Shubnyakov I, Denisov A, Konev V, Gofman I, Starchik D, et al. The experimental study of tissue integration into porous titanium implants. Hip Int. 2020;23:1120700020943481. https://doi.org/10.1177/1120700020943481.

15. Amin Yavari S, van der Stok J, Chai YC, Wauthle R, Tahmasebi Birgani Z, Habibovic $P$, et al. Bone regeneration performance of surface-treated porous titanium. Biomaterials. 2014;35(24):6172-81. https://doi.org/10.1016/j. biomaterials.2014.04.054

16. Garcia-Gareta E, Hua J, Blunn GW. Osseointegration of acellular and cellularized osteoconductive scaffolds: is tissue engineering using mesenchymal stem cells necessary for implant fixation? J Biomed Mater Res A. 2015;103(3):1067-76. https://doi.org/10.1002/jbm.a.35256.

17. Stubinger S, Nuss K, Burki A, Mosch I, le Sidler M, Meikle ST, et al. Osseointegration of titanium implants functionalised with phosphoserinetethered poly (epsilon-lysine) dendrons: a comparative study with traditional surface treatments in sheep. J Mater Sci Mater Med. 2015:26(2): 87. https://doi.org/10.1007/s10856-015-5433-3.

18. Cohen DJ, Cheng A, Kahn A, Aviram M, Whitehead AJ, Hyzy SL, et al. Novel Osteogenic Ti-6Al-4V device for restoration of dental function in patients with large bone deficiencies: design, Development And Implementation. Sci Rep. 2016;6:20493.

19. Liu H, Li W, Liu C, Tan J, Wang H, Hai B, et al. Incorporating simvastatin/ poloxamer 407 hydrogel into 3D-printed porous Ti6Al4V scaffolds for the promotion of angiogenesis, osseointegration and bone ingrowth. Biofabrication. 2016;8(4):045012. https://doi.org/10.1088/1758-5090/8/4/04 5012

20. Xiu P, Jia Z, Lv J, Yin C, Cheng Y, Zhang K, et al. Tailored surface treatment of $3 \mathrm{D}$ printed porous Ti6Al4V by Microarc oxidation for enhanced Osseointegration via optimized bone in-growth patterns and interlocked bone/implant Interface. ACS Appl Mater Interfaces. 2016;8(28):17964-75. https://doi.org/10.1021/acsami.6b05893.

21. Xu JY, Chen XS, Zhang CY, Liu Y, Wang J, Deng FL. Improved bioactivity of selective laser melting titanium: surface modification with micro-/nanotextured hierarchical topography and bone regeneration performance evaluation. Mater Sci Eng C Mater Biol Appl. 2016;68:229-40. https://doi. org/10.1016/j.msec.2016.05.096
22. Tanzer M, Chuang PJ, Ngo CG, Song L, TenHuisen KS. Characterization of bone ingrowth and interface mechanics of a new porous 3D printed biomaterial: an animal study. Bone Joint J. 2019;101-B(6_Supple_B):62-7.

23. Teng FY, Tai IC, Ho ML, Wang JW, Weng LW, Wang YJ, et al. Controlled release of BMP-2 from titanium with electrodeposition modification enhancing critical size bone formation. Mater Sci Eng C Mater Biol Appl. 2019;105:109879. https://doi.org/10.1016/j.msec.2019.109879.

24. Bai H, Zhao Y, Wang C, Wang Z, Wang J, Liu H, et al. Enhanced osseointegration of three-dimensional supramolecular bioactive interface through osteoporotic microenvironment regulation. Theranostics. 2020; 10(11):4779-94. https://doi.org/10.7150/thno.43736.

25. Li L, Shi J, Zhang K, Yang L, Yu F, Zhu L, et al. Early osteointegration evaluation of porous Ti6Al4V scaffolds designed based on triply periodic minimal surface models. J Orthop Translat. 2019;19:94-105. https://doi.org/1 0.1016/j.jot.2019.03.003.

26. Barba D, Alabort E, Reed RC. Synthetic bone: design by additive manufacturing. Acta Biomater. 2019;97:637-56. https://doi.org/10.1016/j.a ctbio.2019.07.049.

27. Murr LE. Open-cellular metal implant design and fabrication for biomechanical compatibility with bone using electron beam melting. J Mech Behav Biomed Mater. 2017;76:164-77. https://doi.org/10.1016/j. jmbbm.2017.02.019.

28. Tan XP, Tan YJ, Chow CSL, Tor SB, Yeong WY. Metallic powder-bed based 3D printing of cellular scaffolds for orthopaedic implants: a state-of-the-art review on manufacturing, topological design, mechanical properties and biocompatibility. Mater Sci Eng C Mater Biol Appl. 2017;76:1328-43. https:// doi.org/10.1016/j.msec.2017.02.094.

29. Martinez-Marquez D, Delmar Y, Sun S, Stewart RA. Exploring Macroporosity of Additively Manufactured Titanium Metamaterials for Bone Regeneration with Quality by Design: A Systematic Literature Review. Materials (Basel). 2020;13(21):4794.

30. Taniguchi N, Fujibayashi S, Takemoto M, Sasaki K, Otsuki B, Nakamura T, et al. Effect of pore size on bone ingrowth into porous titanium implants fabricated by additive manufacturing: an in vivo experiment. Mater Sci Eng C Mater Biol Appl. 2016;59:690-701. https://doi.org/10.1016/j.msec.2015.10. 069.

31. Schober P, Boer C, Schwarte LA. Correlation coefficients: appropriate use and interpretation. Anesth Analg. 2018;126(5):1763-8. https://doi.org/1 0.1213/ANE.0000000000002864.

32. Liebschner MAK. Biomechanical considerations of animal models used in tissue engineering of bone. Biomaterials. 2004;25(9):1697-714. https://doi. org/10.1016/S0142-9612(03)00515-5.

33. Walsh WR, Pelletier MH, Wang T, Lovric V, Morberg P, Mobbs RJ. Does implantation site influence bone ingrowth into 3D-printed porous implants? Spine J. 2019;19(11):1885-98. https://doi.org/10.1016/j.spinee.2019.06.020.

34. Thomas KA, Kay JF, Cook SD, Jarcho M. The effect of surface macrotexture and hydroxylapatite coating on the mechanical strengths and histologic profiles of titanium implant materials. J Biomed Mater Res. 1987;21(12): 1395-414. https://doi.org/10.1002/jbm.820211205.

35. Soballe K. Hydroxyapatite ceramic coating for bone implant fixation. Mechanical and histological studies in dogs. Acta Orthop Scand Suppl. 1993;255:1-58. https://doi.org/10.3109/17453679309155636.

36. Lugovskoy A, Lugovskoy S. Production of hydroxyapatite layers on the plasma electrolytically oxidized surface of titanium alloys. Mater Sci Eng C Mater Biol Appl. 2014;43:527-32. https://doi.org/10.1016/j.msec.2014.07.030.

37. Hanawa T. Titanium-tissue Interface reaction and its control with surface treatment. Front Bioeng Biotechnol. 2019;7:170. https://doi.org/10.3389/ fbioe.2019.00170.

38. Huedo-Medina TB, Sanchez-Meca J, Marin-Martinez F, Botella J. Assessing heterogeneity in meta-analysis: Q statistic or 12 index? Psychol Methods. 2006:11(2):193-206. https://doi.org/10.1037/1082-989X.11.2.193.

\section{Publisher's Note}

Springer Nature remains neutral with regard to jurisdictional claims in published maps and institutional affiliations. 